\title{
Analyzing Land use Changes in Tourism Development Areas: A Case Study of Cultural World Heritage Sites on Java Island, Indonesia
}

\author{
Dyah Lestari Widaningrum ${ }^{1}$, Isti Surjandari ${ }^{1 *}$, Dodi Sudiana ${ }^{2}$ \\ ${ }^{1}$ Department of Industrial Engineering, Faculty of Engineering, Universitas Indonesia, Kampus UI Depok, \\ Depok 16424, Indonesia \\ ${ }^{2}$ Department of Electrical Engineering, Faculty of Engineering, Universitas Indonesia, Kampus UI Depok, \\ Depok 16424, Indonesia
}

\begin{abstract}
Tourism activities and infrastructure development, as responses to expectations from tourists, are generally considered to negatively influence ecosystem services, specifically at tourism sites. Some studies even show that the construction of any infrastructure, such as accommodation facilities and new roads, endangers the authenticity and integrity of World Heritage sites (WHS). Therefore, it is crucial to have insight into the characteristics of land use in tourism areas and the changes that occur, and to ensure ecosystems can continue to provide services. The purpose of this paper is to analyze changes in land use in the areas around tourism sites. This study developed a future land use simulation (FLUS) model to simulate land use changes based on spatial-temporal data on areas around tourist destinations in general and especially around WHS. The FLUS model was applied to simulate the land use changes in tourism development areas in the middle part of Java Island, Indonesia. This study selected six locational factors and three topographic factors to define the transition map outlining the probability of occurrence for conditions and topography on each land use map grid. The model improved using simulation from 2015 to 2018, with an accuracy of $89.99 \%$ and kappa coefficient of 0.8234 . The FLUS model was further employed to simulate the land use changes from 2018 to 2036. The results of the analysis of land use change in tourism locations indicate a significant change from croplands to built-up areas. This analysis was conducted to provide information for policymakers and investors so that they can make the right decisions when developing the infrastructure development plan. Notably for areas whose economic sector is being developed, but also in particular, have areas that must be preserved.
\end{abstract}

Keywords: Cellular automata; Land use; Simulation; Spatial-temporal; Tourism

\section{Introduction}

Tourism was identified as a leading sector in Indonesia's development in the 20152019 National Development Plan (RPJMN), with achievements in the 2019 report reaching the targets for indicators of contributions to GDP, foreign exchange, employment, the competitiveness index, and the number of domestic tourists (Ministry of Tourism, 2019). According to the World Economic Forum, Indonesia acquired a higher rank for the 2019 Travel \& Tourism Competitiveness Index (TTCI), which increased two ratings compared to 2017 (Calderwood and Soshkin, 2019). This condition impacts various aspects of life, from the economy and people's welfare to the environment. 
Development and tourism activities have the potential to damage tourism sites, especially World Heritage sites (WHS), and endanger ecosystem services in general. The increase in tourism requires more space for facilities and activities, with a subsequent loss of natural ecosystems and their services (Lorilla et al., 2018). For example, based on satellite imagery data, it was found that the urban and agricultural areas increased in size around the largest historical tourist sites in Jordan (Ababneh et al., 2019). Changes in land use that occur due to population growth, infrastructural expansions, environmental pollution, and responses to tourist expectations, such as by constructing accommodation facilities (hotels, motels) or new roads, could lead to irreversible damage and ecological equilibrium disruption (Ayhan et al., 2020). The construction of infrastructure and transportation to support facilities and accommodations for tourism development induce vegetation deterioration and bring ecological risks (Yang et al., 2018). Various facilities that can support tourism activities tend to cluster (Widaningrum et al., 2017; Widaningrum et al., 2018), resulting in an area with high social and economic interaction becoming even denser. Another study in a tourism-education and business city also showed a dependence on transportation facilities to fulfill community needs, although the availability and quality of these facilities still need to be improved (Purba et al., 2017). Tourism destinations included in the WHS categories are important to study. Despite the aim of increasing tourism flow at WHS, the government must also ensure that heritage sites in their administrative areas are protected and preserved under the mission of UNESCO's World Heritage Center (2018). Tourism activities and infrastructure development are considered to negatively influence tourism sites, specifically natural and cultural WHS properties in South-East Asia (UNESCO, 2012). Therefore, it is crucial to have an infrastructure development plan to support sustainable tourism and to ensure ecosystems can continue to provide services. Cities that cope with the challenges of both city development and tourism development have a greater opportunity to attain sustainability (Berawi, 2018).

Appropriate planning requires detailed and accurate information to support the decision-making process. Current technological developments support the fulfillment of relevant data availability, including for spatial data. Spatial data are essential to gain knowledge about the spatial characteristics of an entity, as well as its relationship with other entities. The proximity characteristic refers to the first law of geography from Tobler (1970). The availability of spatial data allows for analyzing and simulating changes in land use to estimate the condition of land cover at a specific time, even for future timepoints.

This study aims to analyze changes in land use in the areas around tourism sites. The analysis was conducted to provide information for policymakers and investors so that they can make the right decisions in the infrastructure development plan. Notably for areas whose economic sector is being developed, but also in particular, have areas that must be preserved. Employing spatial data from several sources, this study involved managing and conducting the initial processing with the geographical information system approach, using ArcGIS® Desktop 10.0 for Windows ${ }^{\circledR}$. A future land use simulation (FLUS) model was developed to simulate land use changes based on spatial-temporal data on areas around tourist destinations in general and especially around cultural WHS. Previous studies showed that infrastructure development (including transportation facilities) and topographical conditions significantly affected changes in land use in tourism areas (including WHS). This study examined land use changes with the proximity of built-up areas, transportation facilities (airport, main road, railway station), tourism sites, and topographical factors (elevation, slope, aspect) as the driving factors using the artificial neural network (ANN) approach. The spatial data allocation of prediction results was carried out using the cellular automata (CA) approach. The results of the spatial allocation were used as a basic map for 
the analysis of the proximity between specified land use and tourism locations, which were managed in PostgreSQL. Proximity analysis utilized lines of code/SQL queries to search for spatial elements that were close to a specific perimeter surrounding each tourism site.

\subsection{Spatial-Temporal Analysis}

Current economic conditions that are increasingly service-oriented and continuously changing require a modern analytical approach to decision-making that considers risk, such as modeling and simulation, and that also includes spatial and temporal contexts in its analysis (Chan, 2011). Tobler's first law of geography states that "everything is related to everything else, but near things are more related than distant things" (Tobler, 1970). According to this law, the context of land use implies that the surroundings of a location are related to the land use at that location, but close surroundings have a stronger influence than more remote surroundings. The neighboring influence on land uses built into CA-based land use models based on the neighborhood effects (Vliet et al., 2009).

Mas et al. (2014) previously compared CLUE-S, Dinamica EGO, and IDRISI, and one aspect emphasized was the process of determining land demand. Dinamica and IDRISI (CA_Markov and LCM) use the Markov matrix to calculate the quantity of land use change, while the CLUE-S model estimates the land use demand outside the model. The recently developed FLUS model has been widely used for land use change analysis since 2017. The FLUS model also uses both a CA approach and the ANN approach to identify the relationships between driving factors and land use patterns (Liu et al., 2017b). The FLUS and CLUE-S models can both be integrated with dynamic system simulation results, namely the land demand quantity, but the FLUS model also has tools to predict the amount of land demand using the Markov chain approach (Liang et al., 2018). Additionally, in the FLUS model, constraint growth or restricted areas can be integrated into the model. Based on these strengths, this study used the FLUS model as a basis for analyzing land changes in the tourism area.

\section{Methods}

\subsection{Study Area}

The simulation area lies in the middle part of Java Island and includes several cities/regencies in Central Java Province and Daerah Istimewa (DI) Yogyakarta Province. Interestingly, 3 out of 5 WHS cultures in Indonesia are located in these two provinces, namely Borobudur Temple Compounds, Prambanan Temple Compounds, and Sangiran Early Man Site. The development of cultural heritage, which is included in the World Heritage List, must both consider conservation aspects and support tourism. The Government of the Republic of Indonesia stipulates zoning to create an area that can guarantee sustainability as well as supporting tourism. This condition supports the government effort to maintain the sustainability of the WHS while increasing tourism.

\subsection{Data Processing}

The simulation process in this study used the land use map for the coverage area in 2009, 2015, and 2018. These land use data were collected from the Ministry of Environment and Forestry. The land use classes were re-classified into the following six categories to simplify the model: cropland, forest land, grassland, water area, built-up area, and unused land. This study compared the simulation results for two different periods, to find the best probability model. The first was a simulation from 2009 to 2018 and the second from 2015 to 2018. The probability model with the best accuracy value was used. Previous studies have revealed that various driving factors can impact land use changes. Liu et al. (2018) included 11 driving factors in the process of determining land use policies; these factors 
consisted of distances to provincial roads, highways, railways, banks, drugstores, hotels, markets, restaurants, schools, hospitals, and parks. Wu et al. (2015) calculated the probability map of each land use type by the several driving factors, such as residential density, distance to the urban center, distance to the river, and distance to the road to explore the impact of the changes on the value of ecosystem services. Liu et al. (2017b) derived the driving factors to simulate multiple land uses. The driving factors consisted of terrain data, soil data, climate data, future climate predictions, and ecological zone.

The determination of driving factors depends on the objectives of the simulation study, the characteristics of the area studied, and the availability of data. This research involved the growth of several cities, including Yogyakarta, Solo, and Semarang. Changes in land use for various classes are likely to be affected by changes in built-up land. Therefore, the distance to the built-up area was the main driving factor for this study. The development of tourist sites also influences the growth of the built-up area. Changes in land use may occur not because of the impact of population growth, but to provide tourism support facilities. The distance to tourism sites, as well as the distance to tourism-supporting facilities and infrastructure, are thus also factors driving changes in land use, namely distance to WHS, distance to tourism sites, distance to the airport, distance to the main road, and distance to the railway station. Of all tourism sites reviewed in this study, $41 \%$ of them are categorized as natural tourism sites, which utilize natural resources, such as a mountain, cave, forest, and water recreation. The shape of land surfaces, including their features, are the main attraction of natural tourism. Changes to this topographic factor can affect the sustainability of natural tourist attractions. Conversely, topographical conditions can encourage changes in land use, especially those that occur due to the process of developing tourism facilities. Thus, this study considered the topographical factors of elevation, slope, and aspect as driving factors.
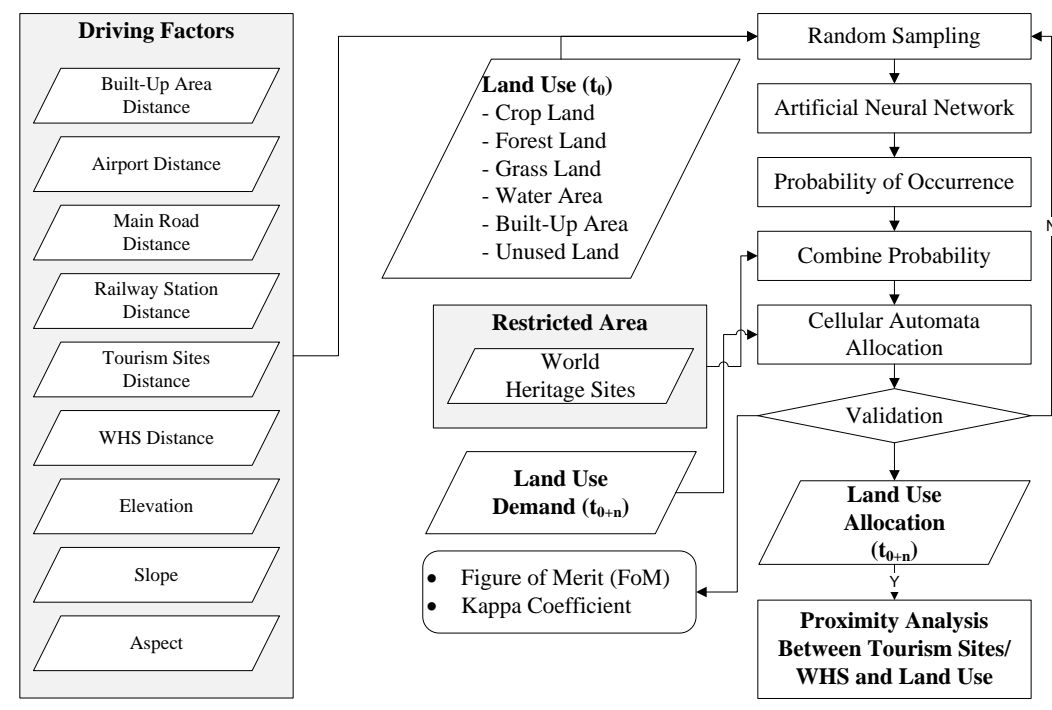

Figure 1 Spatial data analysis process

The spatial data required pre-processing before advancing further in the analysis stages, as illustrated in Figure 1. The various spatial data went through several stages of pre-processing. The initial data processing was performed using ArcGIS ${ }^{\circledR}$ Desktop 10.0 for Windows ${ }^{\circledR}$ to collect, edit, and pre-process spatial data (geographical information system platform). This study used spatial reference the WGS 84/UTM zone 49S, EPSG: 32749. The spatial data were taken from several sources, including geocoding location coordinates. Spatial data manipulations, such as clipping and merging, were conducted to fit the 
coverage area. The next step was to prepare the raster images of the driving factors for the generation of the transition map. This study created several raster images by extracting aspect, slope, and elevation layers from the Digital Elevation Model (DEM) layer, rasterizing land use maps and creating distance maps for each driving factor. The Euclidean Distance function in the ArcGIS Spatial Analyst toolset were applied to generate raster images from vector data, which are locational factor categories. The Surface Analysis function derived the raster elevation, slope, and aspect of the DEM layer. Figure 2 shows the driving factors in raster format.

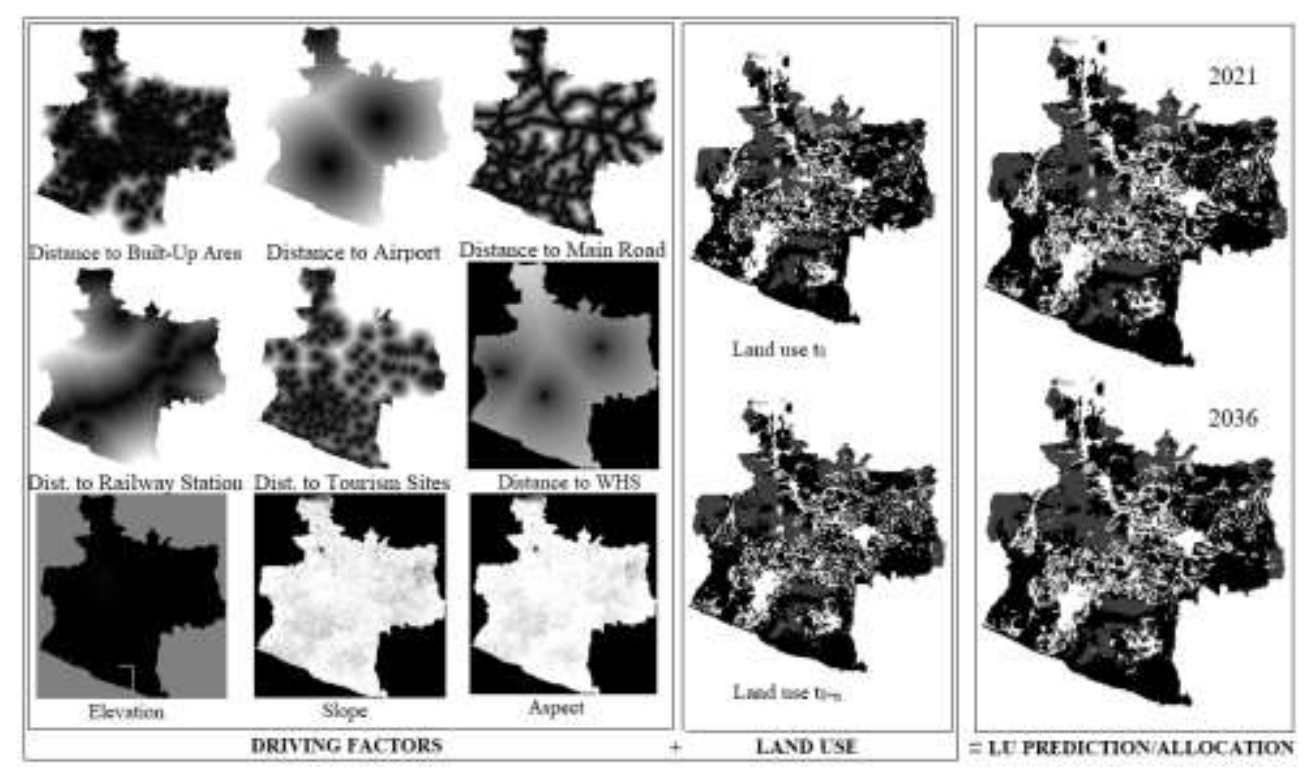

Figure 2 Spatial allocation results based on combined probability for the years 2021 and 2036

Many factors will affect changes in land use; as stated previously, the driving factors will be affected according to the objectives of the study and characteristics of the study area. An adequate analysis must be carried out to test how significantly driving factors influence land use change. This study selected six locational factors and three topographic factors to define the transition map that illustrates the probability of occurrence of conditions and topography on each land use map grid. Spatial data that has been pre-processed was used for the simulation process using GeoSOS-FLUS Version 2.3. The simulation process with the CA approach was implemented in several stages (Liu et al., 2017a). As shown in Figure 1, the first step was estimating the probability of occurrence using the ANN model to define how driving factors affected the initial land use map. The data used were land use raster images and driving factors that have been rasterized.

The next stage included the land use allocation process via the CA approach and the validation process. The simulation process used a combination of the probability of occurrence; the conversion cost, which defines the difficulty level of the land use conversion process; and the influence of neighborhood conditions in the competition mechanism based on CA principles (Liu et al., 2017a). The simulation results were land use maps in raster format. This study used kappa statistics and the figure of merit (FoM) as the measurement parameter. The determination of land demand with the Markov chain approach was conducted to predict future land use. Figure 2 illustrates a raster map that is the simulation result and land use allocation based on driving factors and the actual land use map. The simulated raster map was converted back to vector format using the analysis tools in ArcGIS. The simulation results were converted to shapefile format, then imported into 
PostgreSQL via PostGIS. Thus, the proximity analysis could be conducted using various functions in this program.

\section{Results and Discussion}

\subsection{Spatial and Temporal Simulation of Land Use Change}

Liu et al. (2017b) described how ANNs are applied to approximate the ANN model with non-linear functions that are dependent on predetermined driving factors. The ANN model estimates the probability of occurrence of any land use category in each grid cell. For this study, the estimation model used land use maps for 2009 and 2015 as initial data. The training process for model generation utilized a uniform sampling strategy with a sampling amount of $2 \%$ of valid pixels. The data training process using the ANN model employs the root mean square error (RMSE) parameter for measuring the accuracy of the prediction. The RMSE value for the training results with the initial map for 2009 was 0.1767 and for the initial map for 2015 was 0.1992 . The FLUS model is a land use change simulation model that performs based on multiple CA allocation models, self-adapting inertia, and the competition mechanism (Liu et al., 2017a). Accordingly, the FLUS model incorporates the probability of occurrence (a probability model based on the initial land use map with the driving factors) with the conversion cost and neighborhood conditions to estimate the combined probability for each land grid. This FLUS model can also determine restricted areas. In this study, the WHS were strictly protected areas in accordance with the spatial policy implemented by the government. Therefore, this study generated a binary image, where the value of 0 means that grid cells were restricted to be converted to another type of land use.

Table 1 Validation parameters for the simulation results

\begin{tabular}{lcc}
\hline Measurement Parameter & $2009-2018$ & $2015-2018$ \\
\hline FoM & 0.100877 & 0.0534968 \\
Producer's Accuracy & 0.141765 & 0.0619942 \\
User's Accuracy & 0.232637 & 0.24065 \\
Kappa Coefficient & 0.571338 & 0.823416 \\
\hline Overall Accuracy & 0.75561 & 0.899877 \\
\hline
\end{tabular}

The FLUS model allocates land use change for each grid cell based on combined probability and future land size (land demands) for each land use type. For the initial stage, this study simulated the allocation of land use in 2018. Based on the actual 2018 land use map, the land area for each type of land use was then calculated. The next step was to validate the FLUS model by comparing the actual 2018 land use map with the results of the simulated land use allocation. The process of examining this model was performed for the simulation process between 2009 and 2018, and between 2015 and 2018. The FLUS model employed the kappa statistical and the FoM tools as the parameters of model validation. The validation process entailed comparing the predicted spatial data with actual data. Referring to Landis and Koch (1977), the strength of agreement from kappa statistics for data from 2009 to 2018 was moderate, while data from 2015 to 2018 was almost perfect. However, Pontius et al. $(2004,2008)$ in Liu et al. (2018) explained that the FoM index provides a better picture of the simulation results accuracy. The FoM is calculated from $B /(A+B+C+D)$, where value $A$ is the error due to land use changed is predicted as persistence; value $B$ is the accuracy value of the predicted land change correctly; value $C$ is the error value due to the prediction error in the land use change category; and value D is an error because persistence conditions were predicted to change (Liu et al., 2017b). As 
shown in Table 1, the validation results showed that the simulation results from the FLUS model have acceptable accuracy values. However, the simulation results from 2015 to 2018 showed better accuracy. For the next stage of the simulation process, this study thus used the 2015 land use map.

The FLUS model requires quantitative land demands for each land use category. The top-down approach can be applied in predicting land demands, to be further integrated with the bottom-up approach, the CA approach. This integration process allows various scenarios to predict land requirements. However, it requires an in-depth analysis of the interrelationships of various non-spatial factors that affect land demands based on expert knowledge. This study sought to obtain an initial description of land use changes that occur in the tourism area. Thus, using the Markov chain to predict future land use demand was sufficient, as predictions were calculated based on past trends. GeoSOS-FLUS was used to predict land demand for each land use category. The Markov chain approach using GeoSOSFLUS software predicted every 3 years up to 2036, based on land use change image data from 2015 to 2018.

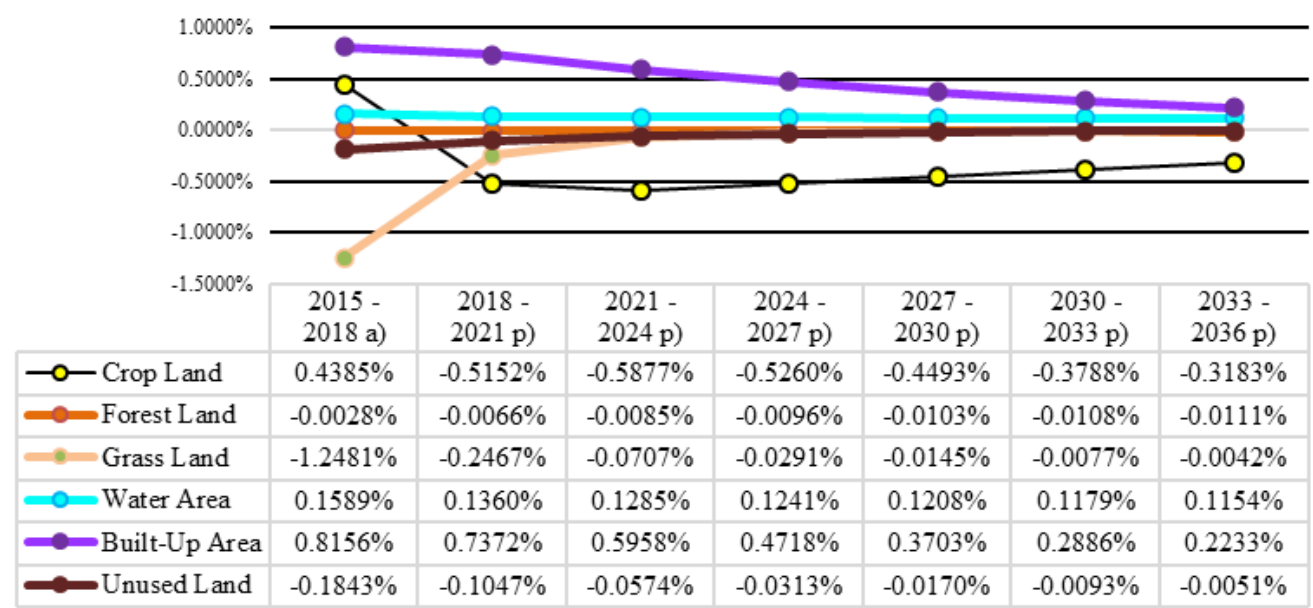

Figure 3 Percentage change in land use per 3-year period (a for actual; $p$ for projected data)

Figure 3 shows the percentage of land changes for each category for every 3 years. A positive percentage shows that land size increased compared to the previous 3 years, and vice versa if the percentage is negative. The land size from the built-up area continued to increase, based on both actual and simulation data, although the percentage decreased from year to year. A similar increase occurred in the water area, although the value of the increase was smaller when compared to the built-up area. Cropland size increased based on actual data, while the simulation results showed a decrease. The amount of land for other categories decreased from year to year.

The results of the land demand simulation for each land use category were then used for the spatial allocation process for land use maps. This stage mirrored the spatial allocation process for the validation stage. The land use prediction maps were later the reference for analyzing land changes of tourism locations and the surrounding areas.

\subsection{Land Use Changes in Tourism Areas}

There were similarities between the findings of land use changes as described in section 3.1., with changes in land use in tourism locations. Based on land area, the built-up area category has consistently increased from year to year, as has the water area category, although the percentage increase remained small. Changes in land use have also occurred in a number of tourism locations. A very significant finding was the increase in the number 
of tourism sites in the built-up area land use category and a decrease in the number of tourism sites in the cropland land use category.

This study covered 439 tourism locations, divided into three categories: cultural tourism, natural tourism, and other tourism. However, for both categories of tourism, there was a year-to-year change in land use from the cropland to the built-up area category.

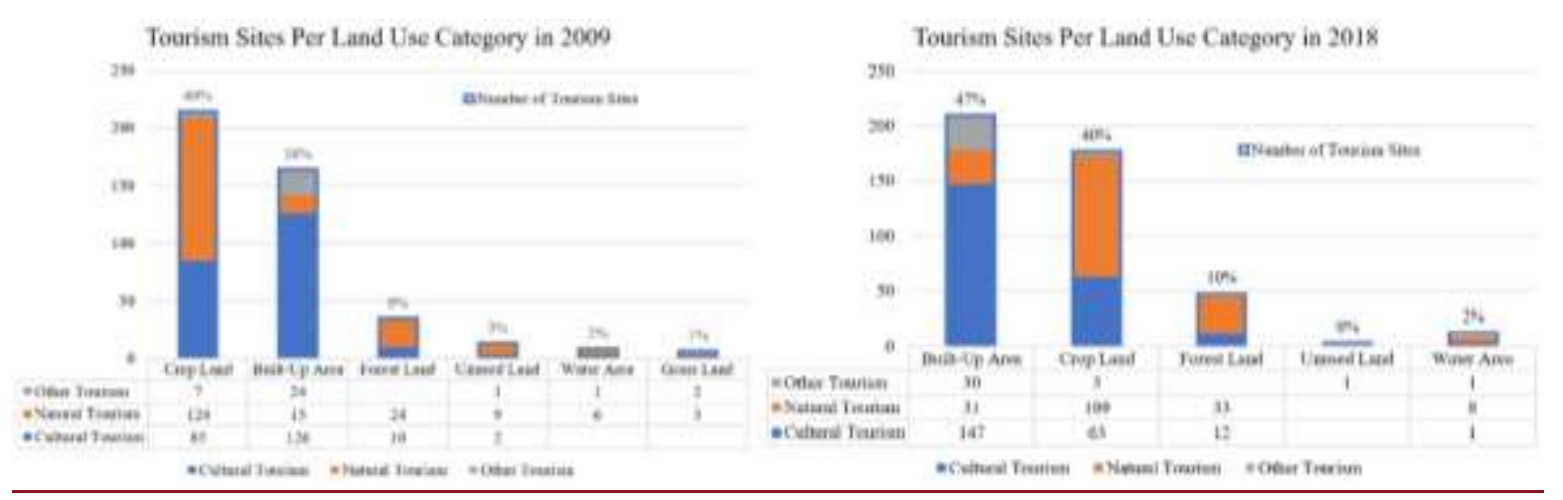

Figure 4 Tourism sites per land use category in 2009 and 2018

For example, the mapping between the number of tourism sites for each category and the land use category-referring to the actual land use map in 2009, 2015, and 2018-is presented in Figure 4. In 2009, 49\% of tourism sites were in the cropland category, while $38 \%$ were in the built-up area category. Interestingly, in 2018, the conditions were almost inversely proportional; $47 \%$ of tourism sites were in the built-up area category, while only $40 \%$ of tourism sites fell in the cropland land use category. If described in the form of scatter plots, changes in land use in tourism locations from 2015 to 2036 created a straight-line pattern of an inverse relationship between the number of land use built-up area categories and the cropland categories.

Based on actual data in 2009, 2015, and 2018, 44 tourism locations turned into a builtup area. Forty-one tourism sites in 2009 were included in the cropland category, 1 location was in the forest land category, 1 location was in the grassland category, and 1 location was in the unused land category. In the 2009 cropland category, 41 tourism sites were included; 24 locations (59\%) were in the DI Yogyakarta Province (occurred in 3 regions), and 17 locations (41\%) were in the Central Java Province (occurred in 1 city and 7 regencies). Bantul Regency (in the province of DI Yogyakarta) has 16 tourism sites (39\% of the total) whose category changed from cropland to built-up area. The regional government indeed assessed these areas as strategic urban and tourism areas by implementing various strategies, including improving facilities and infrastructure.

Several types of cultural tourism sites have changed from croplands to built-up areas, including tourist villages, attractions, cultural heritage, and religious tourism. Several types for the category of natural tourism include water recreation, landscape, agritourism, and cave, while water parks fall under the other tourism category. The Borobudur Compound Temples and Sangiran Early Man Site were part of the cultural heritage category, which changed in the land use category from cropland to built-up area. Meanwhile, since 2009, the Prambanan Compound Temples site fell under the built-up area category for land use.

Most of the natural and cultural resources are inherited resources, such as natural/cultural WHS, species diversity, the attractiveness of natural assets, and intangible cultural heritage expressions. Excessive exploration and exploitation of natural/cultural resources will endanger the sustainability of the environment, so fulfilling the policies and requirements to enhance sustainability is essential to ensure the attractiveness of the 
destination remains. Thus, the analysis of land use change in tourism locations is a contribution this research can make to elevate existing knowledge and provide insight to not only the government responsible for managing spatial planning, but also tourism service providers and tourism support activities.

According to the government responsibility to manage spatial planning, the regional government established a strategic area that functions to allocate space for various socioeconomic activities and environmental preservation activities. Balancing the construction of facilities and infrastructure to support socio-economic activities by preserving the environment remains a complicated responsibility. Given that, based on the findings in this study, will changing croplands into built-up areas endanger the ecosystem services? Could the development of tourism areas that can increase socio-economic growth instead endanger the general environment, especially in a way that negatively impacts the preservation of the cultural heritage sites? Woodhead (2018) argued that technology can be the basis of smart city development with an "up and down" approach. Given that, how can the government and the population jointly increase tourism while maintaining the sustainability of ecosystem services?

\section{Conclusions}

The FLUS model has acceptable accuracy in simulating land use changes from year to year. The locational factors - namely distance to the built-up area, to airport, to the main road, to the railway station, to tourism sites, and to WHS-together with topographic factors (elevation, slope, and aspect) are driving factors for land use change in this study. The simulation results of land use change showed a significant increase in the size of builtup areas from year to year. Another finding of concern in this study was the status of land use from tourism locations that encounter significant changes, from croplands to built-up areas, including cultural WHS.

This study used the Markov chain simulation to predict land demands for each type of land use. The determination of land demands in this study has not yet considered the influence of social, economic, and environmental factors. Further research should consider these three factors and applying several scenarios to produce more information for policymakers. This analysis was conducted to provide information for policymakers and investors so that they can make the right decisions when formulating the infrastructure development plan.

\section{References}

Ababneh, A., Al-Saad, S., Al-Shorman, A., AL Kharouf, R., 2019. Historical Tourist Attractions of Umm Qais, Jordan: GIS and Markov Chain Analyses. International Journal of Historical Archaeology, Volume 23(1), pp. 235-259

Ayhan, C..K., Cengiz Taşlı, T., Özkök, F., Tatll, H., 2020. Land use Suitability Analysis of Rural Tourism Activities: Yenice, Turkey. Tourism Management, Volume 76, 103949

Berawi, M.A., 2018. Managing Sustainable Infrastructure and Urban Development: Shaping a Better Future for ASEAN. International Journal of Technology, Volume 9(7), pp. 12951298

Calderwood, L.U., Soshkin, M., 2019. The Travel \& Tourism Competitiveness Report 2019: Travel and Tourism at a Tipping Point. Switzerland: World Economic Forum

Chan, Y., 2011. Location Theory and Decision Analysis. 2nd Edition, Berlin-Heidelberg: Springer-Verlag

Landis, J.C., Koch, G.G., 1977. The Measurement of Observer Agreement for Categorical Data. 
International Biometrics Society, Volume 33(1), pp. 159-174

Liang, X., Liu, X., Li, D., Zhao, H., Chen, G., 2018. Urban Growth Simulation by Incorporating Planning Policies into a CA-based Future Land use Simulation Model. International Journal of Geographical Information Science, Volume 32(11), pp. 2294-2316

Liu, D., Zheng, X., Wang, H., Zhang, C., Li, J., Lv, Y., 2018. Interoperable Scenario Simulation of Land use Policy for Beijing-Tianjin-Hebei Region, China. Land Use Policy, Volume 75, pp. $155-165$

Liu, X., Li, X., Liang, X., 2017a. GeoSOS-FLUS User's Manual : A Future Land Use Simulation Model by coupling Human and Natural Effects. Guangzhou: Sun Yat-Sen University

Liu, X., Liang, X., Li, X., Xu, X., Ou, J., Chen, Y., Li, S., Wang, S., Pei, F., 2017b. A Future Land use Simulation Model (FLUS) for Simulating Multiple Land use Scenarios by Coupling Human and Natural Effects. Landscape and Urban Planning, Volume 168, pp. 94-116

Lorilla, R.S., Poirazidis, K., Kalogirou, S., Detsis, V., Martinis, A., 2018. Assessment of the Spatial Dynamics and Interactions Among Multiple Ecosystem Services to Promote Effective Policy Making Across Mediterranean Island Landscapes. Sustainability, Volume 10(9), pp. 1-28

Mas, J.F., Kolb, M., Paegelow, M., Olmedo, M.T.C., Houet, T., 2014. Inductive Pattern-based Land Use/Cover Change Models: A Comparison of Four Software Packages. Environmental Modelling \& Software, Volume 51, pp. 94-111

Ministry of Tourism, 2019. Ministry of Tourism Performance Accountability Report 2018. Republic of Indonesia: Ministry of Tourism

Purba, A., Nakamura, F., Herianto, D., Diana, I.W., Jafri, M., Niken, Ch., 2017. Transit System Service Quality in a Tourism-Education City and a Business City. International Journal of Technology, Volume 8(6), pp. 1159-1167

Tobler, W., 1970. A Computer Movie Simulating Urban Growth in the Detroit Region. Economic Geography, Volume 46, pp. 234-240

UNESCO, 2012. Understanding World Heritage in Asia and the Pacific: The Second Cycle of Periodic Reporting 2010-2012. Paris, France: United Nations Educational, Scientific and Cultural Organization

UNESCO's World Heritage Center, 2018. UNESCO World Heritage and Sustainable Tourism Programme. Paris

Vliet, J., White, R., Dragicevic, S., 2009. Modeling Urban Growth using a Variable Grid Cellular Automaton. Computers, Environment and Urban Systems, Volume 33(1), pp. 35-43

Widaningrum, D.L., Surjandari, I., Arymurthy, A.M., 2017. Spatial Data Utilization for Location Pattern Analysis. In: Procedia Computer Science, Volume 124, pp. 69-76

Widaningrum, D.L., Surjandari, I., Sudiana, D., 2018. Spatial Decision Tree Analysis to Identify Location Pattern. In: ACM International Conference Proceeding, pp. 422-429

Woodhead, R., 2018. Building a Smarter City. International Journal of Technology, Volume 9(7), pp. 1509-1517

Wu, M., Ren, X., Che, Y., Yang, K., 2015. A Coupled SD and CLUE-S Model for Exploring the Impact of Land Use Change on Ecosystem Service Value: A Case Study in Baoshan District, Shanghai, China. Environmental Management, Volume 56(2), pp. 402-419

Yang, X., Wang, J., Sun, X., Zhang, H., Li, N., Liu, J., 2018. Tourism Industry-driven Changes in Land Use and Ecological Risk Assessment at Jiuzhaigou UNESCO World Heritage Site. Journal of Spatial Science, Volume 63(2), pp. 341-358 